\title{
Subsea Processing Equipment: A Strategy for Effective Assessment and Selection
}

\author{
Kafayat Oluwatoyin Shobowale ${ }^{1, a}$, Fakhruldin Mohd Hashim ${ }^{2, \text { a }}$, \\ Hilmi Bin Hussien ${ }^{3, \text { a }}$ \\ ${ }^{123}$ Department of Mechanical Engineering, Universiti Teknologi PETRONAS, 31750, \\ Tronoh, Perak, Malaysia \\ ashobowale_g01955@utp.edu.my, bfakhruldin_mhashim@petronas.com.my, \\ chilmi_hussin@petronas.com.my
}

\section{Keywords: Subsea processing, Equipment, Assessment, Selection}

\begin{abstract}
Subsea processing equipment's are deployed in Deepwater / subsea marginal field, fields having challenging reservoir characteristics (which includes: high viscosity, high GVF) in order to economically recover oil and gas. They includes: multiphase booster pump, subsea separation and compression equipment's. These equipment's faces a high level of uncertainty as regards well and reservoir conditions, putting the equipment in an unfavorable condition covering a wide and variable range of processes including transient Flow, variable oil flow, fluid pressures, temperature and gas compression effects. More so, knowledge engineers in different areas are assessing this domain in different ways making the performance parameters and relations to be defined differently when utilizing computer based tools for assessment and selection. A four step process is proposed which are: domain knowledge acquisition, failure data analysis, knowledge model and a knowledge base system will reveal the key components and parameters that are needed to make an optimum decision. The applicability of these four step process is demonstrated in the assessment and selection of subsea multiphase booster pumps.
\end{abstract}

\section{Introduction}

According to a report from Douglas Westwood [1], A survey in year 2000 showed less than $10 \%$ of the companies interviewed expected to install any subsea processing technology within a five-year timescale, In 2003, the number had grown to $75 \%$ and in 2005 , more than $91 \%$ expect installations within 10 years. The capital expenses for these equipment's worldwide is also increasing as reported by Infield [2], from 2006 to 2010, that the cost of subsea booster pump equipment's is about 122 million USD, subsea separation equipment's is about 233 million USD and subsea compression equipment's 100 million USD. According to Hua et al. [3] and Husy [4] more than $90 \%$ of producing wells requires some form of artificial lift or boosting. Conventional onshore processing equipment which has been qualified and operational will not be able to withstand the variation of flow of these wells due to the differences in the environmental conditions the equipment's will operate in as stressed by Husy [4] that thermal requirements are also part of the issues affecting subsea equipment capabilities, thereby requiring equipment's that are performance driven.

According to Haritonov [5], the performance reliability of subsea equipment used by the oil and gas industry for the production of hydrocarbons has a significant impact on production availability and system life cycle costs, Also Fidler [6] reported that the oil and gas industries are behind other industries in achieving top-tier overall equipment effectiveness scores, indicating 
subsea equipment reliability is very important for Deepwater developments. The oil and gas industry also needs to improve reliability and uptime to keep up with its growing demand. Subsea multiphase pumping (pressure boosting), subsea separation and compression are the core and primary technologies that are presently being applied on the seafloor Hua et al.[3], Devegowda and Scott [7].

\section{Literature}

Typically, the oil and gas industry uses industry knowledge, general guidelines, heuristics, intuition, analytical information and information provided by vendors during selection processes which is usually done manually Diwan et al. [8] and Trejo et al. [9]. The criteria for selecting subsea processing equipment remain subjective and are usually influenced by the vendors' data, which could cover the potential limitations of this technology Hua et al. [3]. Existing literature on subsea equipment focuses on a certain type for a specific field application, as most times, the equipment is customised for a particular field application as depicted in all the manufacturer catalogue. According to Hua et al. [3], this does not provide generalized criteria for the selection from among those available in the market.

Previous assessment work on subsea processing equipment especially on the multiphase boosting, separation and gas compression equipment has been based on qualitative assessment where the equipment characteristics, previous installation record and operational characteristics (well parameters, fluid parameters) for a particular field has been used as the key indicator of its functionality (Hua et al.[3], Husy[4], Devegowda and scott [7]). Qualification of some specific components of a particular equipment such as general subsea processing, boosting, Separation and gas compression has also been used in the assessment of these equipment. Only a few of these authors used a quantitative performance measure for reliability predictions of the equipment (Khasanov et al. [11], Alemi et al. [12], and Rehman et al. [13]). Khasanov et al. [11] used RAM and FMEA for technology quantification to measure reliability and identify single point failure mode. Alemi et al. [12] worked on fluid risk analysis and design for operational flexibility to model the steady state and transient performance of the boosting system while Rehman [13] developed a quantitative reliability prediction and performance modeling of multiphase pump system based on ELECTRE. The selection techniques that has been used for subsea processing equipment includes: direct comparison of different equipment groups/simulation Khasanov et al.[11], artificial intelligence technique (Alemi et al. [12], Rehman et al. [13], De La Vega et al. [14], Chan [15], Ridha [16], Espin et al. [17]) and multi-criteria decision making technique with decision matrix (Fatahia et al. [18], Park et al. [19], Wongnapapisan et al. [20]).

\section{Methodology}

In order to optimize assessment and selection of subsea processing equipment so as to increase reliability and eventually profitability a four step method is proposed as shown in figure 2 .

A. Step 1: Domain knowledge acquisition

Domain knowledge acquisition about the process and equipment (basic terminology and concept) on subsea processing system (multiphase boosting, separators and compressor) is needed to be carried out to identify the critical components and parameters. This can be based on: Structure of each equipment groups with its subcomponents and parameters; Manufacturers quality assurance; Literature on similar applications and its reliability; Technical challenges for a particular application (field configuration i.e. reservoir/well parameters and water depth); Economics. 
This will then form the basis to: Prepare and develop interview questions for the equipment operators and manufacturers to obtain important parameters; Obtain additional data that are field/plant specific for reliability estimation. Factors that will influence equipment performance are typically the equipment type and the environment the equipment will be deployed in.

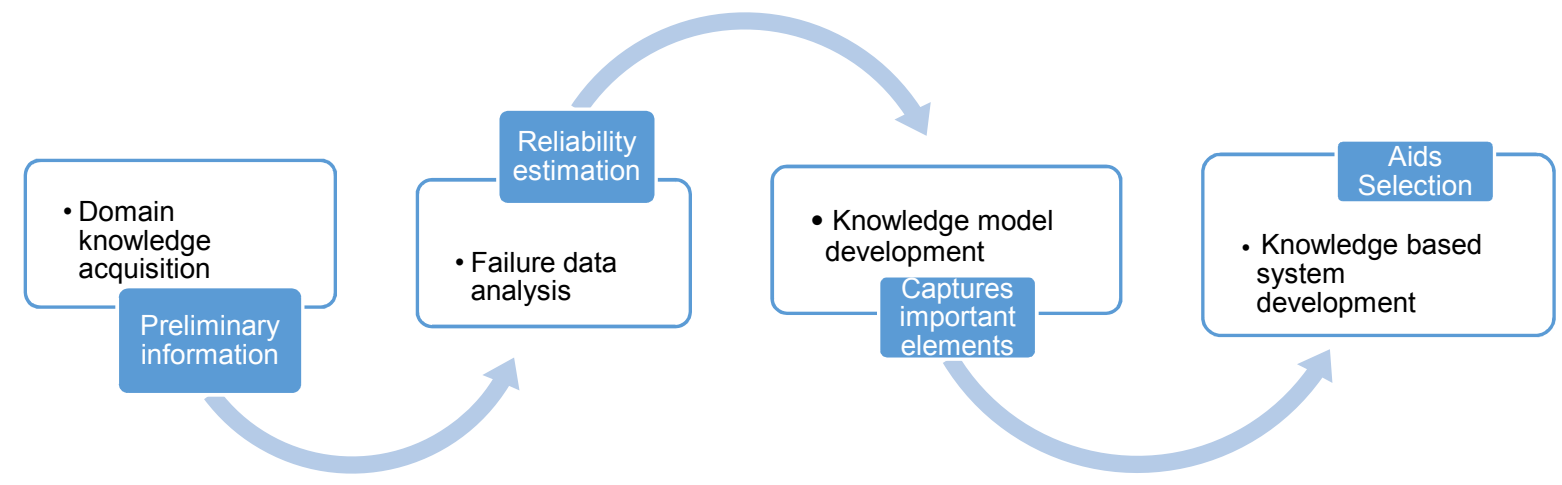

Figure 2: Proposed four step strategy

\section{B. Step 2: Failure data analysis}

To accurately obtain estimates of the reliability of components, collection and statistical analysis of appropriate failure data (in terms of failure rate, mean time between failure or mean time to failure) will give a measure of reliability of component which will then reveal the critical parameters that is needed to be taken into consideration for assessment and selection of subsea processing equipment. Analyse the data obtained in step 1 and carry out performance assessment in form of risk/reliability on subsea multiphase boosting pump, separation and compression equipment's; Estimate critical equipment reliability; Rank each equipment group to identify the critical components based on the result of the reliability analysis. This will reveal a thorough evaluation of the structural integrity of the subsea processing equipment, together with the other environmental factors as stressed by Devegowda and Scott [7] that "The main driver for developing new technology for the subsea processing system is not the seawater environment, but the need to increase the reliability".

\section{Step 3: Development of knowledge model}

Technically, the knowledge model should be buildup of the acquired domain knowledge and the results of the failure data analysis. According to a survey conducted by Bravo et al. [21], one of the major challenges facing the oil and gas industry is the lack of physical models to describe the problem domain. The knowledge model describes the domain by displaying the things that exist/make up the domain which gives it a rich information platform capable of making decisions.

\section{Step 4: Development of a knowledge base system}

Artificial intelligence applications can add value to operations and offers a guideline on which tools to use for each particular oil and gas challenge Bravo et al. [21]. Expert system will be especially useful in the assessment and selection as it is a system that is built on expert rule of thumb which aids decision making. Knowledge for this system can be sourced from the literature, the domain experts, case studies, and experimental data.

\section{Developmental Process for subsea Multiphase booster pump four step strategy}

In the developmental process, data has been collected through survey, the data has been analyzed using Bayesian network, the knowledge model is being developed as ontology in protégé and the knowledge base is being built using the Java expert system shell. Figure 3 and 4, shows the development of the knowledge model after going through the step 1-3, because the boosting 
equipment is part of a larger subsea processing system, assessment and section is done at the systems level. The development of the ontology knowledge model is bases on the creation of classes and subclasses (Figure 3), individuals (Figure 4) and their properties. The final step (Knowledge base via JESS) is omitted due to space constraint.

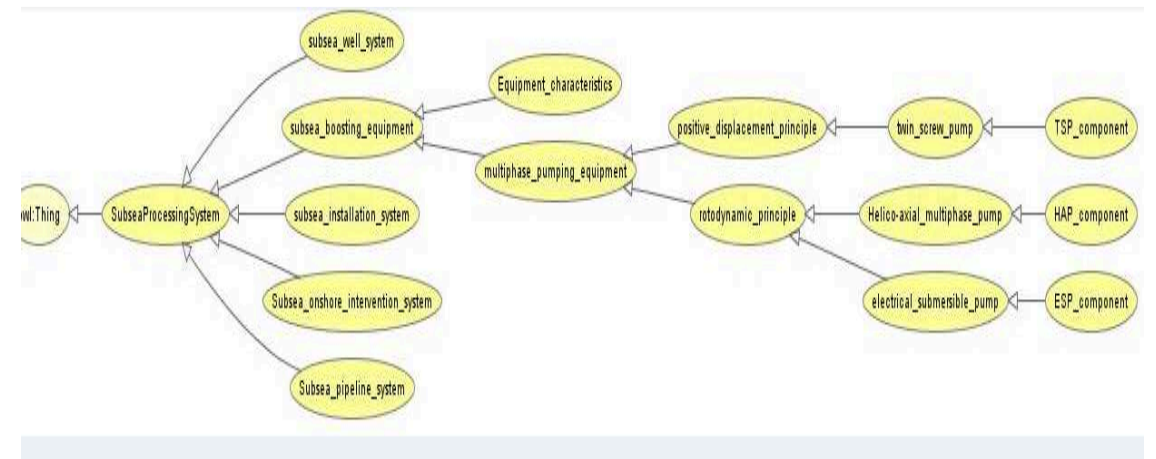

Figure 3: The Ontology Model of Subsea Processing System

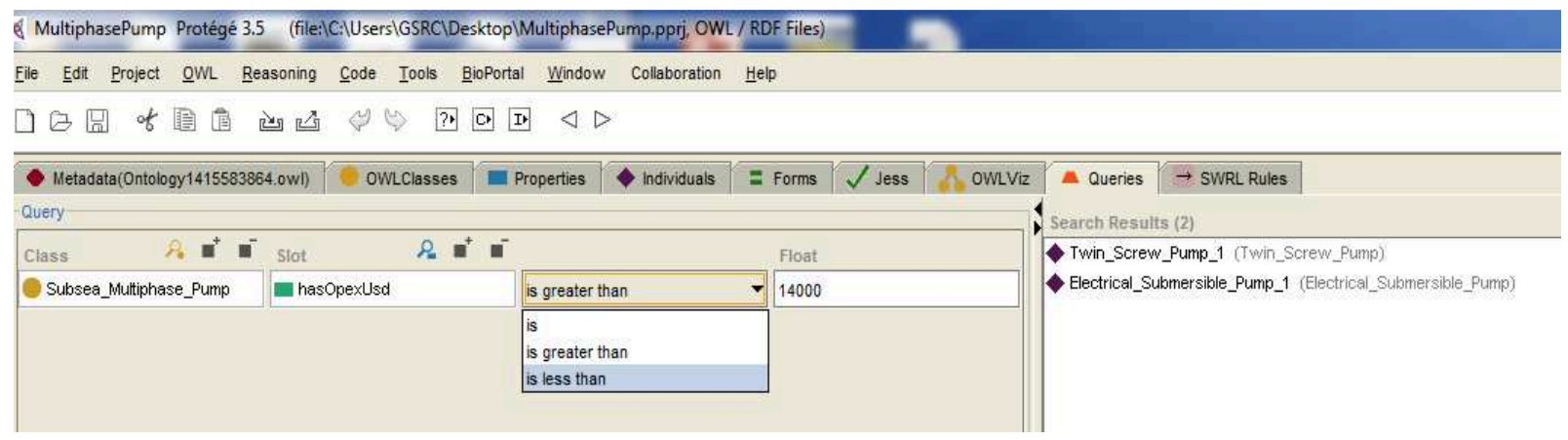

Figure 4: Querying the Ontology Model

\section{Discussion}

Equipment reliability and performance are interwoven, as equipment reliability deals with the structural integrity while equipment performance tends towards ability to yield effective results for the intended field of application. Thermal and mechanical performance of equipment's critical components (such as seal, rotor, impeller), electrical connectors, cables and motors are of upmost importance for subsea processing equipment groups as an improper selection of equipment can reduce production and increase the operating cost significantly. For assessment and selection also of importance are: project economics and equipment reliability. Going through the four step process will ensure a quantitative solid basis on which optimal assessment and selection can be made.

\section{Conclusion}

Employing the four step process, a quantitative assessment and selection of subsea processing equipment can be optimized which can form the basis of suggesting the appropriate equipment by effectively evaluating parameters, and matching the parameters with the equipment capability, well productivity and facility limitation, that can be used to develop a particular oil and gas field. Although the system is still being developed, there are indications that it can effectively be used.

\section{References}

[1] Douglas Westwood. World subsea hardware market forcast 2013-2017.

[2] Infield Global perspectives subsea market report to 2015. Infield Systems Limited, London, (2011), pp 172-173.

[3] G. Hua, G. Falcone, C. Teodoriu, G.L. Morrison, Comparison of Multiphase pumping technologies for subsea and downhole applications. Oil and Gas Facilities, (2012), 36-46. 
[4] S. Husy, Marginal fields: Technology enables profitability / Marginal fields and their Challenges. Presented at Offshore technology conference, Houston, Texas. 2-5 May, 2011.

[5] C.M.R. Haritonov, N. Robertson, J.E. Strutt. The design of subsea production system for reliability and availability. Presented at OTC, Texas, 2009

[6]E. S. Fidler, Asset performance management helps oil and gas companies increase asset availability, improve uptime and empower more intelligent decision making. Offshore Technology Conference in Houston, Texas, USA, (2009).

[7]D. Devegowda, S. L. Scott, An Assessment of Subsea Production Systems. Paper SPE 84045 Presented at The Annual Technical Conference And Exhibition, Denver, Colorado, 2003.

[8] Diwan, P., Kazmi A., and Washid, M., Strategic investment decisions in petrochemical sector. Pentagon energy press, New Delhi. (2009)

[9] J. Moreno-Trejo, R. Kumar, T. Marketset, Mapping factors influencing the selection of subsea petroleum production systems: a case study. Int J Syst Assur Eng Manag (2012), 3(1):6-16

[10] G. Chiesa, R. Eriksen, "Subsea processing - The solution to cost efficient deepwater field developments". Presented at OTC, Texas. (2000)

[11] M.M. Khasanov, Khabibullin, R.A., Pashali, A.A., Semenov, A.A., "Approach to selection of optimal lift technique in the Vankor field", SPE Annual technical Conference and Exhibition, Florence, Italy. (2010).

[12] M. Alemi, Jalalifar H., Kamali G.R., Kilbasi M., A mathematical estimation for artificial lift systems selection based on ELECTRE model. Journal of Petroleum Science and Engineering. Vol 78, pp. 193-200, (2011).

[13] A. Rehman, Soponsakulkaew, N., Bello O., Falcone G., "A Generic model for optimizing the selection of artificial lift methods for liquid loaded gas wells", SPE Annual technical Conf. and Exhibition, Denver, Colorado, USA, (2011).

[14] E. De la Vega, Sandoval G., Garcial M., Nuruz G., Al-Kinani A., Holy R.W., Escalona H., Mota M., Integrating data mining and Expert system for an artificial lift advisory. SPE intelligent Energy Conf. and Exhibition, Utrecht, The Netherlands. (2010).

[15] C.W. Chan, An expert decision support system for monitoring and diagnosis of petroleum production and separation processes. Expert Systems with Applications Vol. 29 pp.131-143, 2005.

[16] B. C. G. Ridha, An expert system for selecting and designing EOR processes, Journal of Petroleum Science And Engineering 27 pp.33-47, 2000

[17] D. A.Espin, Gasbarri, S., and Chasin, J. E., "Expert system for selection of optimum artificial lift method". III Latin America/Caribbean Petroleum Engineering Conference. Buenos Aires, Argentina. April 1994.

[18] E. Fatahia , H. Jalalifar, P. Pourafsharib ,B. Moradi, Selection of the Best Artificial Lift Method for One of the Iranian Oil Field Using Multiple Attribute Decision Making Methods. Int. Journal of Engng and Tech. Volume 2 No. 2, 2012

[19] Park H.Y., Falcone G., Teodoriu C., Decision matrix for liquid loading in gas wells for cost /benefit analysis of lifting options. Journal of natural gas science and engineering, (2009) 1, pp. 7283.

[20] B. Wongnapapisan, S. Flew, F. Boyd, Z. Hassan, Optimizing Brown field redevelopment options using a decision risk assessment: Case study- Bokor field Malaysia. SPE Asia pacific conf. on integrated modelling for asset mgt, KL, Malaysia, 2004.

[21] C. Bravo, L. Saputelli, F. Rivas, A.G. Rerez, M. Nikolaou, G. Zangl, N. Guzman, S. Mohaghegh, G. Nunez, State of the art of Articial intelligence and Predictive analysis in the E\&P industry: A Technology survey. SPE intelligent energy conference, Utrecht, The Netherlands, 27-29 march, 2012 